\section{BMJ Open Respiratory Research}

\title{
Effect of acute respiratory infections in infancy on pulmonary function test at 3 years of age: a prospective birth cohort study
}

\author{
Prawin Kumar, ${ }^{1}$ Aparna Mukherjee, ${ }^{1}$ Shivani Randev, ${ }^{1}$ Guruprasad R Medigeshi, ${ }^{2}$ \\ Kana Ram Jat (1D , ${ }^{1}$ Arti Kapil, ${ }^{3}$ Rakesh Lodha, ${ }^{1}$ Sushil Kumar Kabra (1) ${ }^{1}$
}

To cite: Kumar P, Mukherjee A, Randev S, et al. Effect of acute respiratory infections in infancy on pulmonary function test at 3 years of age: a prospective birth cohort study. BMJ Open Resp Res 2020;7:e000436. doi:10.1136/ bmjresp-2019-000436

- Additional material is published online only. To view please visit the journal online (http://dx.doi.org/10.1136/ bmjresp-2019-000436)

Received 4 April 2019 Revised 27 September 2019 Accepted 3 November 2019

Check for updates

\section{(c) Author(s) (or their} employer(s)) 2020. Re-use permitted under CC BY-NC. No commercial re-use. See rights and permissions. Published by BMJ.

${ }^{1}$ Department of Pediatrics, All India Institute of Medical Sciences, New Delhi, Delhi, India

${ }^{2}$ Vaccine and Infectious Disease Research Center, Translational Health Science and Technology Institute, Faridabad, Haryana, India ${ }^{3}$ Department of Microbiology, All India Institute of Medical Sciences, New Delhi, Delhi, India

Correspondence to Dr Sushil Kumar Kabra; skkabra@hotmail.com

\section{ABSTRACT}

Introduction Acute respiratory infections (ARIs) in infancy may have a long-term impact on the developing respiratory system. We planned a prospective cohort study to determine the impact of ARI during infancy on the pulmonary function test indices at 3 years of age. Methods A cohort of normal, full-term newborns were followed up 6 monthly and during ARI episodes. Infant pulmonary function tests (IPFTs) were performed at baseline and each follow-up visit using tidal breathing flow-volume loop, rapid thoracoabdominal compression (RTC) and raised volume RTC manoeuvres. During each ARI episode, nasopharyngeal aspirates were tested for respiratory pathogens by real-time PCR.

Results We screened 3421 neonates; 310 were enrolled; IPFT was performed in 225 (boys: $125(55.6 \%))$ at 3 years. During infancy, 470 ARI episodes were documented in 173 infants. At 3 years, children with history of any ARI episode during infancy had lower forced expiratory volume in $1 \mathrm{~s}$ $\left(\mathrm{FEV}_{1.0}\right)$, forced expiratory volume in $0.75 \mathrm{~s}\left(\mathrm{FEV}_{0.75}\right)$, forced expiratory volume in $0.5 \mathrm{~s}\left(\mathrm{FEV}_{0.5}\right)$, forced expiratory flow between $25 \%$ and $75 \%$ of $\mathrm{FVC}\left(\mathrm{FEF}_{25-75}\right)$, and maximal expiratory flow at $25 \%$ of FVC $\left(\mathrm{MEF}_{25}\right)$ as compared with those without any ARI episode during infancy. The ratio of tidal expiratory flow (TEF) at $25 \%$ or $50 \%$ of tidal expiratory volume to peak TEF (TEF or TEF $_{25}$ /peak TEF) at 3 years was significantly increased in children who had ARI in infancy.

Conclusions ARI during infancy is associated with impaired pulmonary function indices such as increased resistance and decreased forced expiratory flow and volume at 3 years of age.

\section{INTRODUCTION}

Chronic respiratory disease is a significant cause of morbidity in childhood and later life. ${ }^{1}$ Epidemiological studies reveal that many of such chronic respiratory disorders such as asthma and chronic obstructive pulmonary disease (COPD) in the adults may have their origin in the antenatal period and early childhood. ${ }^{2-5}$ It is a well-known fact that respiratory system continues to grow and develop in the postnatal period, especially during the

\section{Key messages}

This birth cohort study has documented the influence of ARI on infant's pulmonary function test indices as indicated by significantly lower infant pulmonary function test (IPFT) indices for forced expiratory volume and flow rate, and higher indices reflecting airway resistance.

- Apart from respiratory syncytial virus and rhinovirus, human coronavirus, and human metapneumovirus infections were also significantly associated with impairment of IPFT indices.

- This is one of the first prospective birth cohort studies from Asia which has demonstrated objectively the association between ARI in infancy, irrespective of their aetiology, and impaired IPFT indices reflecting flow limitation and increased resistance at 3 years of age.

first 3 years of life making this period exceptionally vulnerable to lung injury. ${ }^{6-9}$

In the last two decades, several innovative methods for the measurement of infant's pulmonary function have been developed and these are playing a vital role in the understanding of normal growth and development of lungs, as well as their longitudinal, follow-up from birth through childhood. ${ }^{89}$ Longitudinal studies have revealed that lung function at birth and in the first 4-6 years of age tracks the lung function throughout life. ${ }^{357}$

Acute respiratory infections (ARIs) during infancy may affect the normal development of the respiratory system which in turn may have an impact on pulmonary function test. ${ }^{5}$ 10-12 ARI during early life, especially with viral aetiology, can lead to development of asthma in childhood and COPD in adulthood. ${ }^{2} 31314$ Although infection with any of the respiratory viruses during infancy may contribute to the development of asthma and COPD in childhood and adulthood, most of the studies have 
focused on respiratory syncytial virus (RSV) and rhinovirus (RV) infections. ${ }^{5} 101315-17$

Elucidating the effect of ARI on developing pulmonary function in infancy and its tracking in childhood and beyond is an exciting research area. It offers the possibility of identification of infants, who after an ARI episode, maybe at an increased risk of developing chronic respiratory diseases; strategies could then be studied in these infants for the prevention of chronic respiratory morbidity. ${ }^{16}{ }^{18}$ However, the majority of the available literature is on RSV and RV infection, lower respiratory tract infection (LRTI) and mainly from the Caucasian and Oriental populations. ${ }^{41013141619}$ There is a scarcity of data describing the association of all types of ARIs of any aetiology with the developing pulmonary functions measured by IPFT.

We hypothesised that ARI during the first year of life might lead to structural changes in the respiratory system, which in turn may be responsible for chronic respiratory morbidity in children. IPFT can objectively document the effect of these structural changes. For this, a prospective study was planned in which, a birth cohort was enrolled and followed up at 6 months' intervals till 3 years of age; at each visit, IPFTs were performed. The primary objective of this study was to document the effect of ARI during infancy on IPFT indices at 3 years of age.

\section{METHODS}

This prospective birth cohort study was conducted in the Department of Pediatrics of a tertiary care institute in north Delhi, India, from August 2012 to March 2017. The study was approved by the Institutional Ethics Committee. Written informed consent was taken from the parents/guardians.

All neonates born at the All India Institute of Medical Sciences, New Delhi during the study period were screened for eligibility. Inclusion criteria were age $\leq 4$ weeks, term (born at $\geq 37$ weeks of gestation) and appropriate for gestational age (weight: 10th-90th centile) babies. ${ }^{20}$ Exclusion criteria were any perinatal insults (eg, birth asphyxia, meconium aspiration, any amount of respiratory distress requiring respiratory support, pathological hyperbilirubinaemia or seizure), known major congenital birth defect, required parenteral antibiotic or fluid, neonatal cholestasis, chronic kidney disease, or inborn error of metabolism and mother having antepartum or postpartum haemorrhage, pre-eclampsia or eclampsia, HIV infected, or parents' refusal for regular follow-up for 3 years. The enrolled babies were followed up every 6 months and also whenever they had ARI episode or any other acute condition. The babies were clinically examined, and anthropometric measurements (weight, length, head circumference) were recorded at enrolment and at each visit.
Patient and public involvement

We did not involve the participants in the formulation of study design, recruitment or conduction of the study. However, we assured them that the results would not reveal any participant identity.

\section{Infant pulmonary function test (IPFT)}

IPFTs were performed with Exhalyzer D (Eco Medics AG, Duernten, Switzerland) as per the American Thoracic Society/European Respiratory Society Task Force recommendations. ${ }^{21-25}$ IPFTs included tidal breathing flow-volume loop (TBFVL), rapid thoracoabdominal compression (RTC) and raised volume rapid thoracoabdominal compression (RVRTC) manoeuvres.

\section{Measurement conditions}

All IPFT manoeuvres were performed in the Pediatric Pulmonary Function Lab, which is well equipped with a central supply of oxygen and resuscitation equipment. The equipment was calibrated daily for atmospheric temperature and pressure and volume with a $100 \mathrm{~mL}$ calibration syringe (M30.9011) provided by the manufacturer. Weight and length/height were recorded using standard methods. ${ }^{26}$ IPFT were postponed for 3-4 weeks if the child had an ARI.

IPFT at enrolment and at 6 months of age were performed in either awake or natural sleep state after breast feeding. Beyond 6 months of age, syrup Triclofos (25-50 mg/ $\mathrm{kg} /$ dose) was used for sedation whenever required. The manoeuvres were performed in the supine position. Baseline TBFVL was completed within 4 weeks of birth, while RTC and RVRTC were first performed once the child was $\geq 8 \mathrm{~kg}$ as per recommendations of the manufacturer of IPFT equipment. IPFTs were repeated at every follow-up visit. The IPFT indices and their physiological interpretation are described in table 1.

\section{Acute respiratory infections}

Parents were advised to visit the hospital whenever their child developed symptoms suggestive of ARI like fever, cold, cough, fast or difficulty in breathing, noisy breathing or chest retraction. Health status of enrolled children was also enquired telephonically at 2-4 weeks interval. If parents expressed difficulty in bringing the child to hospital, the study nurse visited their home and collected the required sample. LRTI was diagnosed during ARI in the presence of fast breathing for age as defined by WHO (respiratory rate: $<2$ months: $\geq 60 /$ min; 2-12 months: $\geq 50 / \mathrm{min}$ ), and upper respiratory tract infections (URTIs) in the absence of fast breathing for age. ${ }^{27}$ Wheezing during these ARI episodes were documented by a paediatrician during the hospital visit. They were treated symptomatically during these episodes, and an antibiotic (Amoxicillin) was only used in case of LRTI. Children were hospitalised if they had inadequate oral intake, not responding to supportive measures, stayed far-away from medical facility and in case of parental 


\begin{tabular}{|c|c|c|c|}
\hline IPFT & IPFT indices & Unit & Physiological interpretation \\
\hline \multirow[t]{4}{*}{ TBFVL } & $\begin{array}{l}\text { Inspiratory time }\left(t_{l}\right) \text {, expiratory time }\left(\mathbf{t}_{\mathrm{E}}\right) \text {, total respiratory time }\left(\mathbf{t}_{\mathrm{tot}}\right) \text {, time to } \\
\text { peak tidal inspiratory or expiratory flow }\left(\mathbf{t}_{\mathrm{PTIF}} \text { or } \mathbf{t}_{\mathrm{PTEF}}\right)\end{array}$ & s & $\begin{array}{l}\text { Time taken to complete } \\
\text { individual manoeuvres }\end{array}$ \\
\hline & Tidal volume $\left(\mathbf{V}_{\mathrm{T}}\right)$, inspiratory or expiratory tidal volume $\left(\mathbf{V}_{\mathrm{l}}\right.$ or $\left.\mathbf{V}_{\mathrm{E}}\right)$ & $\mathrm{mL}$ & Tidal lung volume \\
\hline & $\begin{array}{l}\text { Peak tidal inspiratory or expiratory flow (PTIF or PTEF) } \\
\text { Mid tidal inspiratory or expiratory flow (MTIF or MTEF) } \\
\text { Tidal expiratory flow (TEF) at } 75,50,25 \text { or } 10 \% \text { of tidal expiratory volume } \\
\text { still have to be expired }\left(\mathbf{T E F}_{75}, \mathbf{T E F}_{50}, \mathbf{T E F}_{25} \text { or } \mathbf{T E F}_{10} \text { ) }\right.\end{array}$ & $\mathrm{mL} / \mathrm{s}$ & Flow rate \\
\hline & $\begin{array}{l}\text { Ratio of inspiratory or expiratory time to total respiratory time }\left(t_{\mathrm{t}} / \mathbf{t}_{\text {tot }} \text { or } t_{\mathrm{E}} /\right. \\
\left.\mathbf{t}_{\text {tot }}\right) \text {, inspiratory to expiratory time }\left(t_{/} / t_{\mathrm{E}}\right) \text {, } \\
\text { Peak ratio: time to PTEF to } \mathrm{t}_{\mathrm{E}}\left(\mathrm{t}_{\mathrm{PTEF}} / \mathrm{t}_{\mathrm{E}}\right) \\
\text { Ratio of exhaled volume to PTEF to tidal expiratory volume }\left(\mathbf{V}_{\mathrm{PTEF}} / \mathbf{V}_{\mathrm{E}}\right) \\
\text { Ratio of } \mathrm{TEF}_{75}, \mathrm{TEF}_{50}, \mathrm{TEF}_{25} \text { or TEF } \text { TE }_{10} \text { to peaked tidal expiratory flow (PTEF) }\end{array}$ & $\%$ & Represent airway resistance \\
\hline \multirow[t]{2}{*}{ RTC } & $\begin{array}{l}\text { Maximum expiratory flow at functional residual capacity }\left(\mathbf{V}^{\prime}{ }_{\text {max,FRc }}\right) \\
\text { Maximum expiratory flow at } 50 \% \text { or } 70 \% \text { of expiration }\left(\mathbf{V}_{50}^{\prime} \text { or } \mathbf{V}^{\prime}{ }_{70}\right)\end{array}$ & $\mathrm{mL} / \mathrm{s}$ & Flow rate \\
\hline & Volume to peak expiratory flow $\left(\mathbf{V}_{\mathrm{PEF}}\right)$ & $\mathrm{mL}$ & $\begin{array}{l}\text { Lung volume at partial } \\
\text { expiratory flow-airway } \\
\text { resistance }\end{array}$ \\
\hline \multirow[t]{3}{*}{ RVRTC } & $\begin{array}{l}\text { Forced expiratory volume (FEV), FEV at } 0.5,0.75 \text { or } 1.0 \text { s of the forced } \\
\text { expiration ( } \text { FEV }_{0.5} / \mathrm{FEV}_{0.75} / \mathrm{FEV}_{1.0} \text { ) }\end{array}$ & $\mathrm{mL}$ & $\begin{array}{l}\text { Forced lung volume at given } \\
\text { period }\end{array}$ \\
\hline & $\begin{array}{l}\text { Maximum expiratory flow at } 25 \% \text { or } 10 \% \text { of } \mathrm{FVC}\left(\mathbf{M E F}_{25} \text { or } \mathbf{M E F}_{10}\right) \\
\text { Forced expiratory flow between } 25 \% \text { and } 75 \% \text { of } \mathrm{FVC}\left(\mathrm{FEF}_{25-75}\right) \\
\text { Peak expiratory flow (PEF) }\end{array}$ & $\mathrm{mL} / \mathrm{s}$ & $\begin{array}{l}\text { Forced flow rate representing } \\
\text { airway resistance. }\end{array}$ \\
\hline & $\begin{array}{l}\text { Ratio of forced expiratory volume at } 0.5 \mathrm{~s} \text { to total forced expiratory volume } \\
\text { (FEV } \text {. }_{0.5} \text { FEV) }\end{array}$ & $\%$ & Airway obstruction \\
\hline
\end{tabular}

IPFT, infant pulmonary function testing; RTC, rapid thoracoabdominal compression; RVRTC, raised volume rapid thoracoabdominal compression; TBFVL, tidal breathing flow-volume loop.

concerns, these children received intravenous amoxicillin. For this study, ARI episodes only during the first year of life were considered in analysis.

\section{Microbiological sampling}

In every clinically diagnosed ARI episode, nasopharyngeal aspirate (NPA) was collected to identify the causative respiratory virus(es) using multiplex real-time PCR assay as per the manufacturer's instructions (FTD Respiratory pathogens 21; Fast Track Diagnostics, Luxembourg). The respiratory pathogens (20 viruses and 1 atypical bacterium) detected were influenza $\mathrm{A}$, influenza $\mathrm{A}(\mathrm{H} 1 \mathrm{~N} 1)$ swl, influenza B; human coronavirus (HCoV) NL63, 229E, OC43 and HKU1; parainfluenza 1, 2, 3 and 4; human metapneumovirus (HMPV) A and B; RV; RSV A and $\mathrm{B}$; adenovirus; enterovirus; parechovirus; bocavirus; and Mycoplasma pneumoniae. In cases where multiple viruses were detected from the same sample, the one with the highest CT (threshold cycle) value and amplification in real-time PCR was considered for analysis. For LRTI, apart from NPA, blood for aerobic bacterial culture on sheep blood agar (Biomeriuex) and MacConkey agar (Hi-Media) medium, procalcitonin (PCT) assay using VIDAS B.R.A.H.M.S PCT kit (Biomerieux SA, France), antibodies to Mycoplasma and Chlamydia pneumoniae (EUROIMMUN, Germany) and urine for Streptococcus pneumoniae antigen detection (BinaxNOW, Alere, Ireland) were also performed as per the manufacturers' instructions for the aetiological diagnosis. PCT value $>0.5 \mathrm{ng} / \mathrm{mL}$ was taken as positive which is suggestive of bacterial infection.

\section{Data handling and statistical analysis}

Clinical information during each visit was recorded manually into case record form, from where data were entered into Microsoft Access software. IPFT data were automatically stored in software (SPIROWARE, Eco Medics AG) after each procedure; data of each individual were extracted and managed in Microsoft Access software. Data were managed in Microsoft Excel and analysed using Stata 13 software (Stata, College Station, Texas, USA).

Quantitative variables were summarised using mean and SD if normally distributed; for skewed distribution, median (IQR) were used. IPFT indices at 3 years of age were compared between children who had ARI episodes during infancy and those who did not, using Wilcoxon rank-sum test. The signed-rank test was used to compare the change in IPFT indices from baseline to 3 years of age in the two groups. For multivariate analysis, separate linear regression models were built using the indices that were significantly associated with ARI in bivariate analysis as the dependent variables. Gender, family history of atopy, presence of smoking in the household, weight and height at 3 years of age and the tidal volume at birth were added as covariates for each regression model. The 


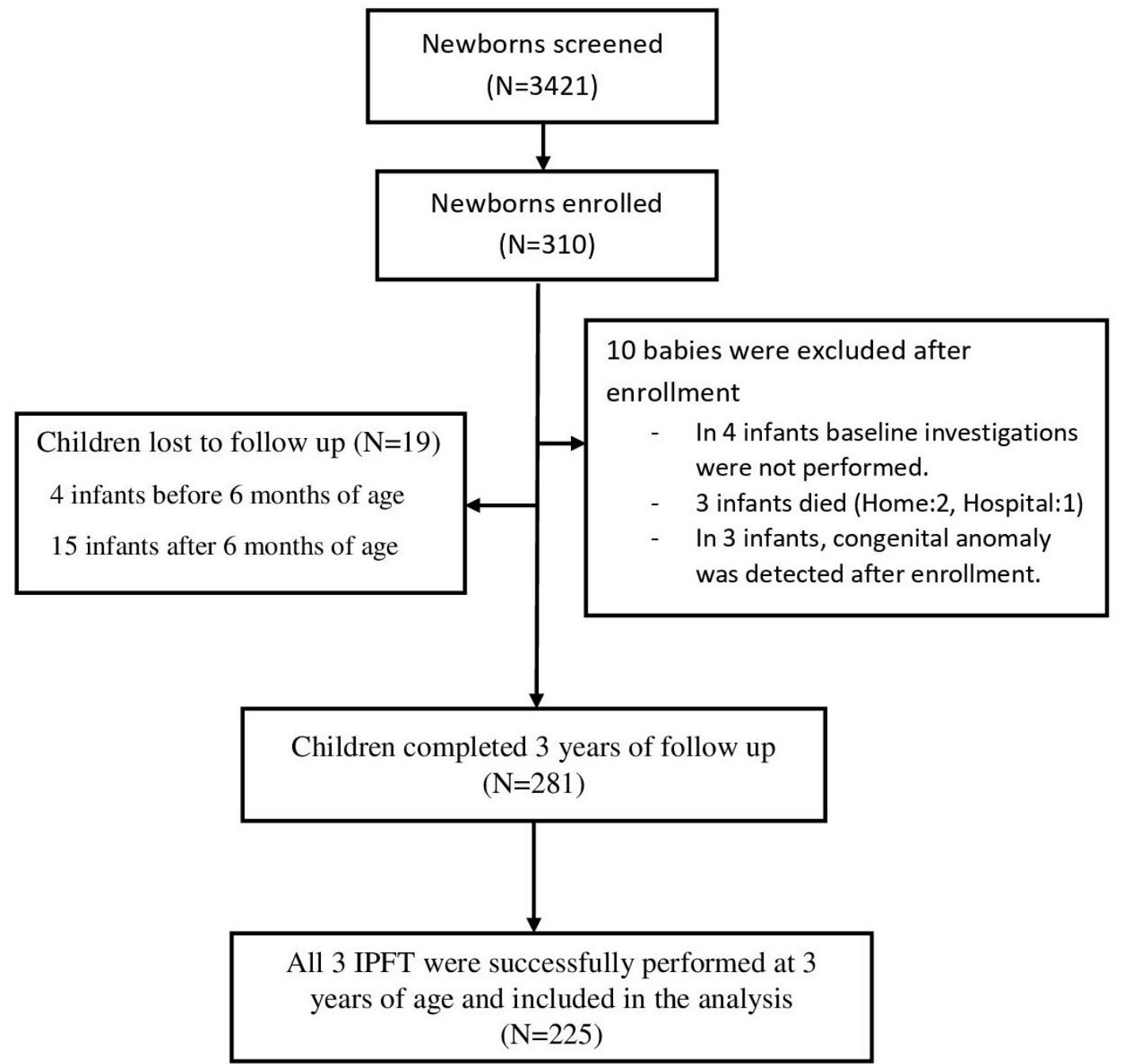

Figure 1 Enrolment and follow-up. IPFT, infant pulmonary function test.

difference was considered statistically significant at the p-value of $<0.05$.

\section{RESULTS}

We enrolled 310 neonates after screening 3421 neonates from August 2012 to May 2014; of these, 281 children $(90.6 \%)$ had completed 3 years of follow-up as on 31 March 2017. IPFT (all three manoeuvres) was successfully performed in $225(80 \%)$ children at 3 years of follow-up (figure 1). The demographic characteristics of children who had completed IPFT at 3 years $(n=225)$ and those who did not complete all three IPFTs, excluded or lost to follow-up $(\mathrm{n}=85)$ were similar (table 2). All further analyses were done on these 225 children. Telephonic consultation was sought 329 times by parents of 82 infants; on 110 of these occasions, children were reported to have symptoms suggestive of ARI, and the caregivers were advised for hospital visit.

A total of 470 ARI episodes were documented in 173 infants; 427 episodes were URTI, while 43 episodes were LRTI. Furthermore, 504 viruses were detected in 380 of the $470(90.8 \%)$ ARI episodes in 154 infants. Mixed viral infections were detected in 110 ARI episodes; single virus in 239, two viruses in 95 and three viruses in 15 ARI episodes. Events related to ARI episodes are summarised in table 3. Baseline TBFVL was performed in all infants $(\mathrm{n}=225)$, while RTC and RVRTC was first performed at 6 months of age in 104 infants (table 4). Absolute change in IPFT indices from baseline to 3 years of age is summarised in online supplementary table 1 .

\section{Effect of ARI during infancy on IPFT indices at 3 years of age}

Among the TBFVL indices, children who had suffered from ARI during infancy did not show a significant change in $\mathrm{V}_{\mathrm{T}}$ and $\mathrm{t}_{\mathrm{PTEF}} / \mathrm{t}_{\mathrm{E}}$ (ratio of time to peak tidal expiratory flow to total expiratory time); other indices, namely $\mathrm{TEF}_{10}$ (tidal expiratory flow at $10 \%$ of tidal expiratory volume), $\mathrm{TEF}_{25}$ (tidal expiratory flow at $25 \%$ of tidal expiratory volume), $\mathrm{TEF}_{25} / \mathrm{PTEF}$ (peak TEF) and $\mathrm{TEF}_{50} / \mathrm{PTEF}$ were significantly increased in comparison with children who did not have documented ARI episode during infancy. RTC indices did not show a significant difference between children with or without ARI episode during infancy. In RVRTC, indices for forced timed lung 
Table 2 Demographic characteristics of enrolled children $(n=310)^{\star}$

\begin{tabular}{|c|c|c|c|}
\hline Demographic parameters & $\begin{array}{l}\text { Children who completed study } \\
\text { at 3years of age }(\mathrm{N}=225)\end{array}$ & $\begin{array}{l}\text { Children did not complete } \\
\text { study at } 3 \text { years of age }(\mathrm{N}=85)\end{array}$ & P-value \\
\hline Boys & $125(55.6)$ & 45 (52.9) & 0.7 \\
\hline \multicolumn{4}{|l|}{ Anthropometry, mean (SD) } \\
\hline \multicolumn{4}{|l|}{ At birth } \\
\hline Weight (kg) & $2.8(0.3)$ & $2.8(0.3)$ & 0.9 \\
\hline Length $(\mathrm{cm})$ & $48.3(1.7)$ & $48.2(1.6)$ & 0.6 \\
\hline \multicolumn{4}{|l|}{ At 3 years } \\
\hline Weight (kg) & $12.9(1.7)$ & $13.3(1.9)$ & 0.3 \\
\hline Height (cm) & $91.3(7.1)$ & $91.9(3.9)$ & 0.8 \\
\hline \multicolumn{4}{|l|}{ Mode of delivery } \\
\hline Vaginal & $152(67)$ & $56(65.8)$ & \multirow[t]{2}{*}{0.3} \\
\hline Caesarean section & $73(33)$ & $29(34.2)$ & \\
\hline History of smoking at home & 78 (34.6) & $18(21.1)$ & 0.2 \\
\hline History of pet at home & $23(10.2)$ & $14(16.4)$ & 0.3 \\
\hline \multicolumn{4}{|l|}{ Place of residence } \\
\hline Urban & $190(84.4)$ & $81(95.3)$ & \multirow[t]{2}{*}{0.05} \\
\hline Rural & $35(15.6)$ & $4(4.7)$ & \\
\hline \multicolumn{4}{|l|}{ Family history of allergy } \\
\hline Asthma & $63(28)$ & $20(23)$ & 0.4 \\
\hline Allergic rhinitis & $72(32)$ & $26(30)$ & 0.1 \\
\hline Atopic dermatitis & $21(9.3)$ & $11(12.9)$ & 0.3 \\
\hline
\end{tabular}

*Values are expressed in $\mathrm{n}(\%)$ unless otherwise specified.

†Children who were excluded, lost to follow-up and unable to perform all IPFT manoeuvres.

IPFT, infant pulmonary function test.

volume, namely $\mathrm{FEV}_{0.5}$ (forced expiratory volume in 0.5 $\mathrm{s}$ ), $\mathrm{FEV}_{0.75}$ (forced expiratory volume in $0.75 \mathrm{~s}$ ), $\mathrm{FEV}_{1.0}$ (forced expiratory volume in $1.0 \mathrm{~s}$ ) and FEV (forced expiratory volume) and indices for forced expiratory flow (FEF) rate, namely $\mathrm{MEF}_{10}$ (maximal expiratory flow at $10 \%$ of $\mathrm{FVC}$ ), $\mathrm{MEF}_{25}$ (maximal expiratory flow at $25 \%$ of FVC) and $\mathrm{FEF}_{25-75}(\mathrm{FEF}$ between $25 \%$ and $75 \%$ of $\mathrm{FVC}$ ) were significantly decreased in children who had ARI in infancy (table 5).

On multivariable analysis using linear regression model, decreased $\mathrm{FEV}_{1.0}$ at 3 years was significantly associated with occurrence of ARI during infancy $(\mathrm{p}=0.009)$, female gender $(\mathrm{p}=0.03)$ and lower weight at 3 years $(\mathrm{p}=0.002)$. Presence of ARI during infancy reduced the $\mathrm{FEV}_{1.0}$ at 3 years by $20.06 \mathrm{~mL}$ (95\% CI: -35.02 to 5.1$)$. Similar results were found in $\mathrm{FEV}_{0.75}(\beta$ coefficient $=-17.99,95 \% \mathrm{CI}$ : -30.37 to $5.5, \mathrm{p}=0.005), \mathrm{FEV}_{0.5}(\beta$ coefficient $=-14.07$, 95\% CI: -23.84 to $4.29, \mathrm{p}=0.005), \mathrm{FEF}_{25-75}$ ( $\beta$ coefficient $=-49.46,95 \% \mathrm{CI}$ : -85.27 to $13.64, \mathrm{p}=0.007)$ and $\mathrm{MEF}_{25}(\beta$ coefficient $=-57.18,95 \%$ CI: -93.89 to 20.46 , $\mathrm{p}=0.002$ ).

\section{Effect of recurrent ARI episodes during infancy on IPFT} indices at 3 years of age

In bivariate analysis, recurrent ARI episodes during infancy $(\geq 2, n=132)$ were associated with increased $t_{\mathrm{PTEF}}$ $(0.47(0.35,0.65)$ vs $0.45(0.36,0.63) \mathrm{s}, \mathrm{p}=0.02), \mathrm{TEF}_{50} /$ $\mathrm{TIF}_{50}(79 \%(68 \%, 87 \%)$ vs $74 \%(68 \%, 88 \%), \mathrm{p}=0.03)$ and $\mathrm{TEF}_{75} / \mathrm{PTEF}(89 \%(85 \%, 93 \%)$ vs $87(80 \%, 92 \%)$, $\mathrm{p}=0.04$ ) at 3 years of age as compared with those who did not have any ARI episode during infancy. However, there were no significant changes in RTC and RVRTC indices with recurrent ARI episodes.

\section{Effect of viral ARI during infancy on IPFT indices at 3 years of age}

TBFVL indices for airway resistance, namely $\mathrm{TEF}_{25} / \mathrm{PTEF}$ and $\mathrm{TEF}_{50} / \mathrm{PTEF}$ were significantly increased in children who had documented viral ARI episode during infancy in comparison to children without history of any ARI episode. No significant difference in any RTC indices was observed in the two groups. RVRTC indices for forced timed lung volume, namely $\mathrm{FEV}_{0.5}, \mathrm{FEV}_{0.75}, \mathrm{FEV}_{1.0}$ and FEV and for forced expiratory flow rate, namely $\mathrm{MEF}_{10}$, $\mathrm{MEF}_{25}$ and $\mathrm{FEF}_{25-75}$ were significantly decreased in children at 3 years of age with documented viral ARI episode during infancy (table 6). 
Table 3 Summary of acute respiratory infection (ARI) events during infancy ( $\leq 1$ year) in study subjects $(\mathrm{N}=225)$

\begin{tabular}{|c|c|}
\hline ARI events & n (\%) \\
\hline Total ARI episodes & 470 \\
\hline Upper respiratory tract infections (URTIs) & $427(90.8)$ \\
\hline Lower respiratory tract infections (LRTIs) & $43(9.2)$ \\
\hline Number of infants who had ARI & $173(76.9)$ \\
\hline URTI & $130 / 173(75.1)$ \\
\hline LRTI & $43 / 173(24.9)$ \\
\hline $\begin{array}{l}\text { Number of children with wheezing during } \\
\text { ARI }\end{array}$ & $57(25.4)$ \\
\hline Infants with recurrent ARI $(\geq 2)$ & $132 / 225(58.6)$ \\
\hline $\begin{array}{l}\text { Number of infants who needed } \\
\text { hospitalisation }(n=27)\end{array}$ & $27 / 225(12)$ \\
\hline With URTI & 6/27 (22.2) \\
\hline With LRTI & $21 / 27(77.8)$ \\
\hline Number of infants with viral ARI $(n=154)$ & $154 / 173(68.4)$ \\
\hline URTI & $114 / 154(74)$ \\
\hline LRTI & $40 / 154(26)$ \\
\hline \multicolumn{2}{|l|}{$\begin{array}{l}\text { Frequency of detected viruses during ARI } \\
\text { episodes }(n=380)^{\star}\end{array}$} \\
\hline Rhinovirus (RV) & $152 / 380(40)$ \\
\hline Respiratory syncytial virus (RSV) & $77 / 380(20.3)$ \\
\hline Parainfluenza & $75 / 380(19.7)$ \\
\hline Human coronavirus & $63 / 380(16.5)$ \\
\hline Human metapneumovirus & $37 / 380(9.7)$ \\
\hline Others viruses & $100 / 380(26.3)$ \\
\hline \multicolumn{2}{|l|}{ Aetiology of LRTI episodes ( $n=43$ ) } \\
\hline Viruses & $40 / 43(93)$ \\
\hline RV & $28 / 40(70)$ \\
\hline RSV & $23 / 40(57.5)$ \\
\hline Evidence of bacterial infection & $32 / 43(74.5)$ \\
\hline Streptococcal pneumoniae & 9/32 (28.2) \\
\hline Chlamydia pneumoniae & 5/32 (15.6) \\
\hline Mycoplasma pneumoniae & $1 / 32(3.1)$ \\
\hline $\begin{array}{l}\text { Only raised procalcitonin level (>0.5 ng/ } \\
\mathrm{mL})\end{array}$ & $17 / 32(53.2)$ \\
\hline Mixed bacterial and viral Infection & $29 / 43(67.4)$ \\
\hline
\end{tabular}

*In 110 ARI episodes, more than one virus was detected.

On multivariable analysis, decreased $\mathrm{FEV}_{1.0}$ at 3 years was significantly associated with detection of virus in ARI in infancy $(\mathrm{p}=0.009)$ and lower weight at 3 years $(p=0.003)$. Presence of virus in ARI during infancy reduced the $\mathrm{FEV}_{1.0}$ by $20.8 \mathrm{~mL}$ ( $95 \% \mathrm{CI}:-35.3$ to 5.3 ). Similar results were found in cases of $\mathrm{FEV}_{0.75}$ ( $\beta$ coefficient $=-18.36,95 \%$ CI: -31.36 to 5.36, $\mathrm{p}=0.006), \mathrm{FEV}_{0.5}$ ( $\beta$ coefficient $=-14.51,95 \%$ CI: -24.76 to $4.25, p=0.006)$, $\mathrm{FEF}_{25-75}(\beta$ coefficient $=-55.28,95 \% \mathrm{CI}:-89.2$ to 21.33 , $\mathrm{p}=0.002)$ and $\mathrm{MEF}_{25}(\beta$ coefficient $=-63.25,95 \% \mathrm{CI}$ : -93.24 to $28.26, \mathrm{p}<0.001$ ).
Detection of virus in ARI in infancy was also associated with an increase in $\mathrm{TEF}_{50} / \mathrm{PTEF}$ ( $\beta$ coefficient $=1.96$, 95\% CI: 0.29 to $3.63, \mathrm{p}=0.02$ ) and $\mathrm{TEF}_{25} / \mathrm{PTEF}$ ( $\beta$ coefficient $=3.0,95 \%$ CI: 0.19 to $5.81, \mathrm{p}=0.03$ ), when adjusted for gender, family history of atopy, weight and baseline IPFT indices.

\section{Effect of individual viruses detected in ARI during infancy on IPFT at 3 years of age}

Similar effects on TBFVL and RVRTC indices were also observed in ARI with RV, RSV, HCoV and HMPV infection during infancy. Only HMPV infection during infancy leads to a significant change in RTC indices $\mathrm{V}_{\text {max, FRC }}^{\prime}$ at 3 years of age, which was higher ( $\beta$ coefficient $=44.71$, $95 \%$ CI: 10.83 to $78.58, \mathrm{p}=0.01$ ) as compared with those who had no ARI during infancy (see online supplementary file 1 , supplementary table 2 ).

Effect of LRTI during infancy on IPFT indices at 3 years of age A total of 43 children had a history of LRTI during infancy. $\mathrm{TEF}_{50} / \mathrm{PTEF}$ (89.5 vs $86.9, \mathrm{p}=0.006$ ) was higher in children with LRTI during infancy than children without a history of ARI during infancy. There was no significant difference in other TBFVL, RTC and RVRTC indices between them (data are not shown).

\section{Effect of wheezing episodes during infancy on IPFT indices at 3 years of age}

A total of 57 infants with ARI episodes had documented wheezing; there was no significant difference in TBFVL, RTC and RVRTC indices between children with wheezing during ARI episode and those without a history of ARI during infancy (data not shown).

\section{Effect of other factors on IPFT indices at 3 years of age}

There was no significant effect of bacterial, mixed bacterial virus and mixed viral infection on IPFT indices. Hospitalisation was required in only 27 (12\%) infants with no significant effect on IPFT indices at 3 years. There was no effect of various socioeconomic variables (living accommodation, parents education, history of smoking at home, source of cooking fuel, number of family member) on IPFT indices at 3 years of age in bivariate analysis (data are not shown).

\section{DISCUSSION}

In this prospective birth cohort study, we could demonstrate that children who developed ARI in infancy had lower forced time expiratory volume and flow rates at 3 years of age and higher $\mathrm{TEF}_{25} / \mathrm{PTEF}$ and $\mathrm{TEF}_{50} / \mathrm{PTEF}$ representing higher airway resistance as compared with those who had no ARI in infancy.

Most of the available literature mainly focuses on alteration in pulmonary function test in school children with a history of LRTI, bronchiolitis or RSV/RV infection during 
Table 4 Baseline IPFT indices in enrolled children

\begin{tabular}{|c|c|c|c|c|c|c|}
\hline IPFT & IPFT indices & Unit & $\begin{array}{l}\text { Enrolled children } \\
(\mathrm{n}=225), \\
\text { median (IQR) }\end{array}$ & $\begin{array}{l}\text { Children who had ARI } \\
\text { episode during infancy } \\
\text { ( } n=173 \text { ), } \\
\text { median (IQR) }\end{array}$ & $\begin{array}{l}\text { Children who did not have } \\
\text { ARI episode during infancy } \\
\text { ( } n=52 \text { ), } \\
\text { median (IQR) }\end{array}$ & P value ${ }^{*}$ \\
\hline \multirow[t]{12}{*}{ TBFVL } & $\mathrm{V}_{\mathrm{T}}$ & $\mathrm{mL}$ & $7(6-9)$ & $7(6-9)$ & $7(6-9)$ & 0.5 \\
\hline & $\mathrm{V}_{\mathrm{T}} / \mathrm{kg}$ & $\mathrm{mL} / \mathrm{kg}$ & $2.7(2.1-3.1)$ & $2.7(2.2-3.0)$ & $2.7(2.1-3.2)$ & 0.5 \\
\hline & $t_{E} / t_{\text {tot }}$ & $\%$ & $52.5(50-55.6)$ & $52.5(49.7-55)$ & $53(50-56.5)$ & 0.2 \\
\hline & $\mathrm{t}_{\mathrm{PTEF}} / \mathrm{t}_{\mathrm{E}}$ & $\%$ & 36.6 (30.9-44.3) & 36.5 (32.3-44.5) & 34.7 (25-39.6) & 0.007 \\
\hline & $\mathrm{TEF}_{10}$ & $\mathrm{~mL} / \mathrm{s}$ & $13(11-16)$ & $13(11-16)$ & $12.5(10-16)$ & 0.3 \\
\hline & $\mathrm{TEF}_{25}$ & $\mathrm{~mL} / \mathrm{s}$ & $17(13-20)$ & $17(14-20)$ & $16(12.5-19)$ & 0.5 \\
\hline & $\mathrm{TEF}_{50}$ & $\mathrm{~mL} / \mathrm{s}$ & $20(17-24)$ & $19(17-24)$ & $21(17-24)$ & 0.5 \\
\hline & MTEF & $\mathrm{mL} / \mathrm{s}$ & $14(12-17)$ & $14(12-17)$ & $14(11-17)$ & 0.9 \\
\hline & TEF $_{10} / \mathrm{PTEF}$ & $\%$ & $59.1(51.2-65.7)$ & $59.1(53.1-66.2)$ & $54.8(47.7-62.5)$ & 0.008 \\
\hline & $\mathrm{TEF}_{25} / \mathrm{PTEF}$ & $\%$ & $72.6(66.3-78.7)$ & $73.1(67.9-79.2)$ & $70.3(64.8-76.7)$ & 0.008 \\
\hline & $\mathrm{TEF}_{50} / \mathrm{PTEF}$ & $\%$ & $89.2(85.1-92.6)$ & 89 (85.2-92.2) & $90.4(85.2-93.0)$ & 0.4 \\
\hline & $\mathrm{V}_{\text {PTEF }} \mathrm{N}_{\mathrm{E}}$ & $\%$ & $37.5(33.4-44.5)$ & $37.5(33.3-44.4)$ & $33.3(31.6-45.4)$ & 0.02 \\
\hline RTC & $\mathrm{V}_{\text {max,FRC }}^{\prime}$ & $\mathrm{mL} / \mathrm{s}$ & $45(0-70)$ & $45(0-70)$ & $60(30-85)$ & 0.2 \\
\hline \multirow[t]{8}{*}{ RVRTC } & $\mathrm{FEV}_{0.5}$ & $\mathrm{~mL}$ & 45.7 (35.7-82.4) & $47.2(39.8-74.8)$ & $43.8(19.3-43.8)$ & 0.4 \\
\hline & FEV $_{0.75}$ & $\mathrm{~mL}$ & 55.5 (43.8-62.3) & $56.8(46.2-65.4)$ & $48.9(31.8-61.5)$ & 0.3 \\
\hline & $\mathrm{FEV}_{1.0}$ & $\mathrm{~mL}$ & $68.1(51-82.9)$ & $74.8(56.2-81.7)$ & $61.4(44.3-84.2)$ & 0.6 \\
\hline & FEV & $\mathrm{mL}$ & $63.9(53.4-81.4)$ & $62.3(53.4-81.4)$ & 65.5 (46.6-86.8) & 0.5 \\
\hline & $\mathrm{MEF}_{25}$ & $\mathrm{~mL} / \mathrm{s}$ & $65(45-110)$ & $65(50-100)$ & $45(40-75)$ & 0.2 \\
\hline & $\mathrm{MEF}_{10}$ & $\mathrm{~mL} / \mathrm{s}$ & $40(35-65)$ & $40(35-65)$ & $35(30-60)$ & 0.2 \\
\hline & $\mathrm{FEF}_{25-75}$ & $\mathrm{~mL} / \mathrm{s}$ & 80.8 (51-134.2) & 80.8 (52.5-107) & $56.2(44.3-97.5)$ & 0.3 \\
\hline & PEF & $\mathrm{mL} / \mathrm{s}$ & 200 (145-265) & 205 (150-340) & $175(100-220)$ & 0.1 \\
\hline
\end{tabular}

${ }^{*}$ Comparison is between children who had ARI during infancy and those who did not have any ARI episode in infancy. $\mathrm{ARI}$, acute respiratory infection; $\mathrm{FEF}_{25-75}$, forced expiratory flow between $25 \%$ and $75 \%$ of FVC; FEV, forced expiratory volume; FEV ${ }_{0.5}$, $\mathrm{FEV}_{0.75}, \mathrm{FEV}_{1.0}$, forced expiratory volume in $0.5 / 0.75 / 1 \mathrm{~s}$; IPFT, infant pulmonary function test; $\mathrm{MEF}_{25} / \mathrm{MEF}_{10}$, maximum expiratory flow at $25 \%$ or $10 \%$ of FVC; MTEF, mid tidal expiratory flow; PEF, peak expiratory flow; PTEF, peak tidal expiratory flow; RTC, rapid thoracoabdominal compression; RVRTC, raised volume rapid thoracoabdominal compression; TBFVL, tidal breathing flow-volume loop; $\mathrm{TEF}_{10}$ or $\mathrm{TEF}_{25}$ or TEF ${ }_{50} / \mathrm{PTEF}$, the ratio of $\mathrm{TEF}_{10}, \mathrm{TEF}_{25}$ or $\mathrm{TEF}_{50}$ to peaked tidal expiratory flow; $\mathrm{TEF}_{10} / \mathrm{TEF}_{25} / \mathrm{TEF}_{50}$, tidal expiratory flow when $10 \% / 25 \% / 50 \%$ of tidal volume remaining for expiration; $t_{E} / t_{\text {tot }}$, ratio of expiratory time to total respiratory time; $t_{\mathrm{PTEF}} / \mathrm{t}_{\mathrm{E}}$, the ratio of time to peak tidal expiratory flow to total expiratory time; $V_{\text {max. FRC }}^{\prime}$, maximal flow at functional residual capacity; $V_{\text {PTEF }} N_{E}$, ratio of exhaled volume to PTEF to tidal expiratory volume; $\mathrm{V}_{\mathrm{T}}$, tidal volume; VT/kg, tidal volume per unit bodyweight.

infancy or early childhood. 4101213172829 The measurement technique for PFT in these studies are heterogeneous with usage of different techniques, such as RTC, RVRTC, body plethysmography, impulse oscillometry, helium dilution and single breath occlusion. ${ }^{7} 91130$

In our study, we have attempted to evaluate the association between ARI of any aetiology in infancy with pulmonary function at 3 years of age using IPFT manoeuvres of TBFVL, RTC, RVRTC in a cohort of Indian children. At baseline, there were no significant differences in RVRTC and RTC indices between children who had and did not have ARI episodes during infancy; rather some of the TBFVL indices are lower in children who did not have any ARI episode during infancy. In this cohort, we could demonstrate that forced expiratory indices, such as $\mathrm{FEV}_{1.0}, \mathrm{FEV}_{0.75}, \mathrm{FEV}_{0.5}, \mathrm{FEF}_{25-75}$ and $\mathrm{MEF}_{25}$ were significantly lower in children at 3 years of age with documented ARI episode during infancy after adjusting for current weight, height, gender and baseline tidal volume.
TBFVL indices like $\mathrm{TEF}_{25} / \mathrm{PTEF}$ and $\mathrm{TEF}_{50} / \mathrm{PTEF}$ were significantly higher in children at 3 years of age with ARI episode during infancy while there was no significant change in RTC indices. Similar changes were also observed in children with viral ARI, especially with RSV, $\mathrm{RV}, \mathrm{HCoV}$ and HMPV during infancy. These changes seem to be the result of increased small airway resistance after ARI episodes.

Earlier studies have mostly focused on LRTI and the influence of RSV or RV infection; association of increased airway resistance, asthma or recurrent wheezing episodes was observed in many of these studies. ${ }^{410} 1314$

A birth cohort study 'Childhood Origin of Asthma' from Wisconsin, USA, had shown that infection with RSV $(\mathrm{OR}=2.6)$, RV $(\mathrm{OR}=9.8)$ or both $\mathrm{RV}$ and $\mathrm{RSV}(\mathrm{OR}=10)$ led to increased risk of development of asthma at 6 years of age. Another longitudinal study from Perth, Australia, 'The Childhood Asthma Study' observed that infection with RSV or RV in the first year of life was a risk factor 
Table 5 Effect of ARI during infancy on IPFT indices at 3 years of age $(n=225)$

\begin{tabular}{|c|c|c|c|c|c|}
\hline IPFT & IPFT indices & Unit & $\begin{array}{l}\text { Children with ARI episode(s) } \\
\text { during infancy ( } n=173 \text { ), } \\
\text { median (IQR) }\end{array}$ & $\begin{array}{l}\text { Children without } \\
\text { documented ARI episode } \\
\text { during infancy ( } n=52) \text {, } \\
\text { median (IQR) }\end{array}$ & P-value \\
\hline \multirow[t]{7}{*}{ TBFVL } & $\mathrm{V}_{\mathrm{T}} / \mathrm{kg}$ & $\mathrm{mL} / \mathrm{kg}$ & $11.3(9.7-13.5)$ & $11.6(10.2-13.8)$ & 0.7 \\
\hline & MTEF & $\mathrm{mL} / \mathrm{s}$ & $130(107-157)$ & $120(98-138)$ & 0.05 \\
\hline & $t_{\text {PTEF }} / t_{E}$ & $\%$ & $39.6(30.5-50.1)$ & 37.7 (29.6-46.8) & 0.19 \\
\hline & $\mathrm{TEF}_{25}$ & $\mathrm{~mL} / \mathrm{s}$ & $153(124-185)$ & $135(110-173)$ & 0.02 \\
\hline & $\mathrm{TEF}_{10}$ & $\mathrm{~mL} / \mathrm{s}$ & $121(97-148)$ & 107 (82-139) & 0.04 \\
\hline & $\mathrm{TEF}_{25} / \mathrm{PTEF}$ & $\%$ & 79.7 (72.1-85.9) & 76.1 (68.6-83.8) & 0.04 \\
\hline & TEF $_{50} / \mathrm{PTEF}$ & $\%$ & $89.8(86.1-93.1)$ & $87.3(85.5-89.2)$ & 0.002 \\
\hline RTC & $\mathrm{V}_{\text {max,FRC }}^{\prime}$ & $\mathrm{mL} / \mathrm{s}$ & $57.5(0-105)$ & $50(0-95)$ & 0.8 \\
\hline \multirow[t]{8}{*}{ RVRTC } & $\mathrm{FEV}_{0.5}$ & $\mathrm{~mL}$ & $58.2(41.6-81.6)$ & $68(45.3-101.8)$ & 0.04 \\
\hline & $\mathrm{FEV}_{0.75}$ & $\mathrm{~mL}$ & $79.4(58.1-106.9)$ & $89.9(69.6-125.1)$ & 0.02 \\
\hline & $\mathrm{FEV}_{1.0}$ & $\mathrm{~mL}$ & $96.8(74.4-124.8)$ & $112.5(77.3-139.7)$ & 0.04 \\
\hline & FEV & $\mathrm{ml}$ & $119.4(85.6-144.3)$ & 137 (117.9-164.5) & 0.004 \\
\hline & $\mathrm{MEF}_{25}$ & $\mathrm{~mL} / \mathrm{s}$ & $125(90-185)$ & $177.5(100-310)$ & 0.01 \\
\hline & $\mathrm{MEF}_{10}$ & $\mathrm{~mL} / \mathrm{s}$ & $80(60-135)$ & $130(70-260)$ & 0.003 \\
\hline & $\mathrm{FEF}_{25-75}$ & $\mathrm{~mL} / \mathrm{s}$ & $154.7(103.6-216.2)$ & 212.5 (123.2-301.9) & 0.01 \\
\hline & PEF & $\mathrm{mL} / \mathrm{s}$ & $252.5(180-355)$ & $282.5(205-400)$ & 0.14 \\
\hline
\end{tabular}

$\mathrm{FEF}_{25-75}$, forced expiratory flow between $25-75 \%$ of $\mathrm{FVC}$; FEV, forced expiratory volume; $\mathrm{FEV}_{0.5} / \mathrm{FEV}_{0.75} / \mathrm{FEV}_{1.0}$, forced expiratory volume in $0.5 / 0.75 / 1.0 \mathrm{sec}$, maximum expiratory flow at $25 \%$ or $10 \%$ of $\mathrm{FVC}\left(\mathrm{MEF}_{25} / \mathrm{MEF}_{10}\right)$; IPFT, infants pulmonary function test; MTEF, mid tidal expiratory flow; PEF, peak expiratory flow; RTC, rapid thoracoabdominal compression; RVRTC, raised volume rapid thoracoabdominal compression; TBFVL, tidal breathing flow-volume loop; $\mathrm{TEF}_{10}$ or $\mathrm{TEF}_{25}$ or $\mathrm{TEF}_{50} / \mathrm{PTEF}$, ratio of $\mathrm{TEF}_{10}$, $\mathrm{TEF}_{25}$ or $\mathrm{TEF}_{50}$ to peaked tidal expiratory flow; $\mathrm{TEF}_{10} / \mathrm{TEF}_{25} / \mathrm{TEF}_{50}$, tidal expiratory flow when $10 / 2550 \%$ of $V_{\mathrm{T}}$ remaining for expiration; $\mathrm{t}_{\mathrm{PTEF}} / \mathrm{t}_{\mathrm{E}}$, the ratio of time to peak tidal expiratory flow to total expiratory time; $\mathrm{V}_{\text {max, FRC }}$, maximal flow at functional residual capacity; $\mathrm{V}_{\mathrm{T}} / \mathrm{Kg}$, tidal volume per unit bodyweight.

for asthma at 5 years of age. ${ }^{31}$ A review by Drysdale et al concluded that RSV LRTI during infancy leads to reduced lung function indices, namely $\mathrm{FEV}_{1.0}, \mathrm{FEV} / \mathrm{FVC}$, peak expiratory flow rate and increased residual volume and airway resistance on follow-up even in early adulthood. ${ }^{32}$ Korppi et al in a prospective study of 20 years follow-up observed abnormal lung function (lower FEV\% and $\mathrm{MEF}_{50}$ ) in children with a history of RSV infection in infancy. ${ }^{330}$ A study from Madrid, Spain, had observed that infection with HMPV during infancy was a strong risk factor for the development of asthma in 3-5 years of age $(\mathrm{OR}=15.9)$, followed by RSV bronchiolitis $(\mathrm{OR}=10.1){ }^{34}$ In the present study, we observed that all viral ARIs, irrespective of the specific aetiology, influenced the IPFT indices at a later stage. Apart from RSV and RV, children with documented HMPV and $\mathrm{HCoV}$ infection during infancy also had lower FEV and flow rate indices at 3 years of age.

A birth cohort study from Tucson, Arizona, had observed that infants $(\mathrm{n}=123)$ with poor airway function during early infancy (measured by $\mathrm{V}_{\text {max. FRC }}^{\prime}$ ) had continued to have lower values for $\mathrm{FEV}_{1.0}, \mathrm{FEF}_{25-75}$ and $\mathrm{FEV}_{1.0} / \mathrm{FVC}$ ratio at 22years of age after adjusting for age, sex, weight and height. ${ }^{5}$ In our cohort, baseline tidal volume measured in the neonatal period did not affect the IPFT indices at 3 years of age, as seen in the adjusted analysis.

In our cohort, ARI with wheezing during infancy were not associated with IPFT indices in children at 3 years of age. A study from Tucson, Arizona, had observed that wheezing in less than 3 years of age lead to reduced $\mathrm{FEV}_{1.0}$, $\mathrm{FEV}_{1.0} / \mathrm{FVC}$ and $\mathrm{FEF}_{25-75}$ through the age of 16 years. ${ }^{35}$ Another study from Finland used impulse oscillometry in 103 children at $5-7$ years of age with history of bronchiolitis with wheezing in the first 6 months of life. They concluded that airway resistance or reactance at $5 \mathrm{~Hz}$ was abnormal in $20 \%$ of children as compared with normal Finnish height-based reference range, but the change was only transient as only $1 \%$ of them had persistent abnormality till preschool age. ${ }^{30}$ These studies indicate that wheezing during infancy may affect PFT in the long run; we need to follow-up our cohort further to document the effect of wheezing on PFT.

In our cohort, we did not observe significant change in $\mathrm{V}_{\mathrm{T}}$ and $\mathrm{t}_{\mathrm{PTEF}} / \mathrm{t}_{\mathrm{E}}$ in children at 3 years of age with ARI, with or without viral infection during infancy. Studies have reported conflicting results on the influence of ARI/ wheezing on $\mathrm{t}_{\mathrm{PTEF}} / \mathrm{t}_{\mathrm{E}}$. Clarke et al performed a prospective study in 94 infants using TBFVL, and partial expiratory flow-volume concluded that $\mathrm{t}_{\mathrm{PTEF}} / \mathrm{t}_{\mathrm{E}}$ is not a very 
Table 6 Effect of any viral ARI during infancy on IPFT indices at 3 years of age

\begin{tabular}{|c|c|c|c|c|c|}
\hline IPFT & IPFT indices & Unit & $\begin{array}{l}\text { Children with any viral ARI } \\
\text { during infancy ( } n=154) \text {, } \\
\text { median (IQR) }\end{array}$ & $\begin{array}{l}\text { Children without ARI during infancy } \\
\text { ( } n=52) \text {, median (IQR) }\end{array}$ & P-value \\
\hline \multirow[t]{6}{*}{ TBFVL } & $\mathrm{V}_{\mathrm{T}} / \mathrm{kg}$ & $\mathrm{mL} / \mathrm{kg}$ & $11.3(9.7-13.6)$ & $11.6(10.2-13.8)$ & 0.8 \\
\hline & $\mathrm{TEF}_{10}$ & $\mathrm{~mL} / \mathrm{s}$ & $123(99-151)$ & $107(82-139)$ & 0.02 \\
\hline & $\mathrm{TEF}_{25}$ & $\mathrm{~mL} / \mathrm{s}$ & $155(126-186)$ & $135(11-173)$ & 0.02 \\
\hline & MTEF & $\mathrm{mL} / \mathrm{s}$ & $131(108-158)$ & $120(98-138)$ & 0.04 \\
\hline & $\mathrm{TEF}_{25} / \mathrm{PTEF}$ & $\%$ & $79.7(72.1-85.8)$ & $76.1(68.4-83.4)$ & 0.03 \\
\hline & TEF $_{50} / \mathrm{PTEF}$ & $\%$ & $89.6(86-93)$ & $87.3(89.2)$ & 0.02 \\
\hline RTC & $\mathrm{V}_{\text {max,FRC }}^{\prime}$ & $\mathrm{mL} / \mathrm{s}$ & $60(0-105)$ & $50(0-95)$ & 0.7 \\
\hline \multirow[t]{7}{*}{ RVRTC } & $\mathrm{FEV}_{0.5}$ & $\mathrm{~mL}$ & $58.2(41-79.8)$ & $68(45.3-101.8)$ & 0.03 \\
\hline & $\mathrm{FEV}_{0.75}$ & $\mathrm{~mL}$ & 79.5 (55.6-105.8) & $89.9(69.6-125.1)$ & 0.03 \\
\hline & $\mathrm{FEV}_{1.0}$ & $\mathrm{~mL}$ & $98.6(73.4-124.8)$ & $112.2(77.3-139.7)$ & 0.04 \\
\hline & FEV & $\mathrm{mL}$ & $119.8(85.6-144.3)$ & $137.1(117.9-164.5)$ & 0.006 \\
\hline & $\mathrm{FEF}_{25-75}$ & $\mathrm{~mL} / \mathrm{s}$ & $154.7(102.3-212.1)$ & 212.5 (123.2-301.9) & 0.01 \\
\hline & $\mathrm{MEF}_{25}$ & $\mathrm{~mL} / \mathrm{s}$ & $125(90-180)$ & $177.5(100-310)$ & 0.008 \\
\hline & $\mathrm{MEF}_{10}$ & $\mathrm{~mL} / \mathrm{s}$ & $80(60-130)$ & $130(70-260)$ & 0.004 \\
\hline
\end{tabular}

$\mathrm{FEF}_{25-75}$, forced expiratory flow between $25 \%$ and $75 \%$ of FVC; FEV ${ }_{0.5}{ }_{0.75} L_{1.0}$, forced expiratory volume in $0.5 / 0.75 / 1$ sec; FEV, forced expiratory volume; IPFT, infants pulmonary function test; $\mathrm{MEF}_{25} \mathrm{MEF}_{10}$, maximum expiratory flow at $25 \%$ or $10 \%$ of FVC; MTEF, mid tidal expiratory flow; RTC, rapid thoracoabdominal compression; RVRTC, raised volume rapid thoracoabdominal compression; TBFVL, tidal breathing flow-volume loop; $\mathrm{TEF}_{25}$ or $\mathrm{TEF}_{10}$, tidal expiratory flow when $25 \%$ or $10 \%$ of $V_{\mathrm{T}}$ remaining for expiration; $\mathrm{TEF}_{25}$ or $\mathrm{TEF}_{50} / \mathrm{PTEF}$, ratio of $\mathrm{TEF}_{25}$ or $\mathrm{TEF}_{50}$ to peaked tidal expiratory flow; $\mathrm{V}_{\text {max,FRC }}$, maximal flow at $\mathrm{FRC}$; VT, tidal volume.

sensitive index in detection of airway obstruction. ${ }^{36} \mathrm{~A}$ plethysmography-based study by Zhang et al in 444 children from 1 to 36 months of age reported that $\mathrm{t}_{\mathrm{PTEF}} / \mathrm{t}_{\mathrm{E}}$ was significantly lower in a wheezing group than in the control group. ${ }^{11}$

LRTI episodes in our cohort did not show significant association with RTC and RVRTC indices; however, $\mathrm{TEF}_{50} / \mathrm{PTEF}$ was significantly increased in comparison to children who did not have documented ARI during infancy. Evidence in literature both support and refute this observation. A recent study from Cape Town, South Africa, did lung function at 6 weeks and 1 year of age in 648 children and observed that repeated LRTI episodes were independently associated with decreased $\mathrm{V}_{\mathrm{T}}$, increased respiratory rate and increased lung clearance index. ${ }^{12} \mathrm{~A}$ study by Strope $e t$ al in 159 children (6-18 years of age) with history of LRTI during preschool age observed that boys with a history of wheezy LRTI had lower $\mathrm{FEV}_{1.0}$ and $\mathrm{FEV}_{1.0} / \mathrm{FVC}$; however, children without wheezy LRTI did not show any significant impact in PFT indices. ${ }^{28}$

\section{Strengths of the study}

It was a well-designed, prospective birth cohort study with minimal dropout rates and regular follow-up, including almost all respiratory tract infections during infancy. Effort was made to identify the aetiology of all ARIs in infancy, including virus, chlamydia, mycoplasma and other bacteria. Hence, we could also explore the association of infection with viruses like HMPV and HCoV and IPFT indices at a later stage. Instead of focusing only on
LRTI, we have included all ARIs of infancy, majority of which were URIs. State-of-the-art IPFTs were performed by trained personnel in keeping with the standard requirements, thus generating robust, reliable data regarding lung functions.

\section{Limitation}

Documentation of ARI episodes may be missing for some infants as their parents might not have informed or did not report to the hospital during the episodes. However, we telephonically contacted the parents from time to time to minimise such events. Besides ARI episodes, there might be other associated factors like genetics and environmental factors (indoor or outdoor pollution) which may affect pulmonary functions and these factors had not been considered here. In our study, LRTI was defined as per the WHO definition of pneumonia; chest X-ray of all children suspected of LRTI was not done due to ethical reasons.

\section{CONCLUSIONS}

ARI during infancy can affect the developing respiratory system. At 3 years of age, in our cohort, significantly lower FEV and flow rate indices were associated with ARI episode in infancy, female gender and low current weight. Apart from RSV and RV, other viruses like HMPV and $\mathrm{HCoV}$ infections during infancy also had a significant impact on pulmonary function at 3 years. 
Acknowledgements We thank Satheesh Thomas, Rakesh, Ritu Dubey and Rajat Prakash who had contributed to this study.

Contributors SKK and RL: conceptualised and designed the study, developed protocol and drafted the manuscript: PK and SR: enrolled patients, collected and analysed data, reviewed literature and prepared initial draft of the manuscript. AM: collected and analysed data, reviewed literature and manuscript preparation. GRM, AK: laboratory assays, data analysis, and manuscript preparation. KRJ: data analysis, reviewed literature and manuscript preparation. All authors had critically revised and approved the final version of the manuscript.

Funding The study was funded by the Department of Biotechnology (DBT), Government of India.

Competing interests None declared.

Patient consent for publication Not required.

Provenance and peer review Not commissioned; externally peer reviewed.

Data availability statement All data relevant to the study are included in the article or uploaded as supplementary information.

Open access This is an open access article distributed in accordance with the Creative Commons Attribution Non Commercial (CC BY-NC 4.0) license, which permits others to distribute, remix, adapt, build upon this work non-commercially, and license their derivative works on different terms, provided the original work is properly cited, appropriate credit is given, any changes made indicated, and the use is non-commercial. See: http://creativecommons.org/licenses/by-nc/4.0/.

ORCID iDs

Kana Ram Jat http://orcid.org/0000-0003-3642-246X

Sushil Kumar Kabra http://orcid.org/0000-0003-2616-9157

\section{REFERENCES}

1 Pearce N, Aitt-Khaled N, Beasley R, et al. Worldwide trends in the prevalence of asthma symptoms: phase III of the International study of asthma and allergies in childhood (Isaac). Thorax 2007;62:758-66.

2 Svanes C, Sunyer J, Plana E, et al. Early life origins of chronic obstructive pulmonary disease. Thorax 2010;65:14-20.

3 Sly PD, Bush A. From the cradle to the grave: the early-life origins of chronic obstructive pulmonary disease. Am J Respir Crit Care Med 2016;193:1-2.

4 Lemanske RF. The Childhood Origins of Asthma (COAST) study. Pediatr Allergy Immunol 2002;13:38-43.

5 Stern DA, Morgan WJ, Wright AL, et al. Poor airway function in early infancy and lung function by age 22 years: a non-selective longitudinal cohort study. The Lancet 2007;370:758-64.

6 Stocks J, Hislop A, Sonnappa S. Early lung development: lifelong effect on respiratory health and disease. Lancet Respir Med 2013;1:728-42.

7 Calogero C, Sly PD. Developmental physiology: lung function during growth and development from birth to old age. In: Frey UMP, ed. Paediatric lung function. Sheffield, United Kingdom: European Respiratory Society, 2010: 1-15.

8 Stocks J. Applications and future directions of infant pulmonary function testing. Paediatr Pulm Funct TestingProg Respir Res Basel 2005;33:78-91.

9 Mohtasham L, Panitch HB. Current approaches in infant pulmonary function testing. Curr Pediatr Rep 2014;2:9-17.

10 Zomer-Kooijker K, van der Ent CK, Ermers MJJ, et al. Increased risk of wheeze and decreased lung function after respiratory syncytial virus infection. PLoS One 2014;9:e87162-8.

11 Zhang $X$, Jiang $G$, Wang $L$, et al. Lung function measurements using body plethysmography in young children with acute lower respiratory tract infection. Zhonghua er ke za zhi $=$ Chinese $J$ Pediatr 2014;52:525-30.

12 Gray DM, Turkovic L, Willemse L, et al. Lung function in African infants in the Drakenstein child health study. impact of lower respiratory tract illness. Am J Respir Crit Care Med 2017;195:212-20.

13 Saglani S. Viral infections and the development of asthma in children. Therapeutic Advances in Infection 2013;1:139-50.

14 Jartti T, Gern JE. Role of viral infections in the development and exacerbation of asthma in children. J Allergy Clin Immunol 2017; 140:895-906.

15 Matsumoto K, Inoue H. Viral infections in asthma and COPD. Respir Investig 2014;52:92-100.

16 Jackson DJ. Early-Life viral infections and the development of asthma: a target for asthma prevention? Curr Opin Allergy Clin Immunol 2014;14:131-6.

17 van der Zalm MM, Uiterwaal CSPM, Wilbrink B, et al. The influence of neonatal lung function on rhinovirus-associated wheeze. $\mathrm{Am} \mathrm{J}$ Respir Crit Care Med 2011;183:262-7.

18 Ahanchian H, Jones CM, Chen Y-sheng, et al. Respiratory viral infections in children with asthma: do they matter and can we prevent them? BMC Pediatr 2012;12:147.

19 Vandini S, Calamelli E, Faldella G, et al. Immune and inflammatory response in bronchiolitis due to respiratory syncytial virus and rhinovirus infections in infants. Paediatr Respir Rev 2017;24:60-4.

20 Lubchenco LO, Hansman C, Boyd E. Intrauterine growth in length and head circumference as estimated from live births at gestational ages from 26 to 42 weeks. Pediatrics 1966;37:403-8.

21 Bates JHT, Schmalisch G, Filbrun D, et al. Tidal breath analysis for infant pulmonary function testing. Eur Respir J 2000;16:1180-92.

22 Sly PD, Tepper R, Henschen M, et al. Tidal forced expirations. Eur Respir J 2000;16:741-8.

23 Conditions M. Respiratory function measurements in infants: measurement conditions. American thoracic Society/European respiratory Society. Am J Respir Crit Care Med 1995;151:2058-64.

24 Beydon N, Davis SD, Lombardi E, et al. An official American thoracic Society/European respiratory Society statement: pulmonary function testing in preschool children. Am J Respir Crit Care Med 2007;175:1304-45.

25 ATS/ERS Statement. Raised volume forced expirations in infants - Guidelines for current practice. Am J Respir Crit Care Med 2005;172:1463-71.

26 Willis TA. Aspinall Bs MRCPCH nm. preventing child obesity: a long-term evaluation of the Henry approach. Community Pract 2013;86:23-7.

27 World Health Organization (WHO). Pocket book of hospital care for children: guidelines for the management of common childhood illinesses. 2nd ed, 2013.

28 Strope GL, Stewart PW, Henderson FW, et al. Lung function in school-age children who had mild lower respiratory illnesses in early childhood. Am Rev Respir Dis 1991;144:655-62.

29 Pullan CR, Hey EN. Wheezing, asthma, and pulmonary dysfunction 10 years after infection with respiratory syncytial virus in infancy. BMJ 1982;284:1665-9.

30 Lauhkonen E, Koponen P, Nuolivirta K, et al. Lung function by impulse oscillometry at age 5-7 years after bronchiolitis at age 0-6 months. Pediatr Pulmonol 2015;50:389-95.

31 Kusel MMH, de Klerk NH, Kebadze T, et al. Early-Life respiratory vira infections, atopic sensitization, and risk of subsequent development of persistent asthma. J Allergy Clin Immunol 2007;119:1105-10.

32 Drysdale SB, Milner AD, Greenough A. Respiratory syncytial virus infection and chronic respiratory morbidity - is there a functional or genetic predisposition? Acta Paediatr 2012;101:1114-20.

33 Korppi M, Piippo-Savolainen E, Korhonen K, et al. Respiratory morbidity 20 years after RSV infection in infancy. Pediatr Pulmonol 2004;38:155-60.

34 García-García ML, Calvo C, Casas I, et al. Human metapneumovirus bronchiolitis in infancy is an important risk factor for asthma at age 5. Pediatr Pulmonol 2007;42:458-64.

35 Morgan WJ, Stern DA, Sherrill DL, et al. Outcome of asthma and wheezing in the first 6 years of life follow-up through adolescence. Am J Respir Crit Care Med 2005;172:1253-8.

36 Clarke JR, Aston H, Silverman M. Evaluation of a tidal expiratory flow index in healthy and diseased infants. Pediatr Pulmonol 1994;17:285-90. 